\title{
Optimization of the Production Process of Bishop's Crown Pepper (Capsicum baccatum var.) Hydroalcoholic Extract
}

\author{
Luís Paulo Firmino Romão da Silva ${ }^{1}$, Mailson Gonçalves Gregório ${ }^{1}$, Alexandre José M. Queiroz ${ }^{1}$, \\ Rossana Maria F. Figueirêdo ${ }^{1}$, Alícia Nayana dos S. L. de Brito ${ }^{1}$, Nágela Maria H. Mascarenhas ${ }^{1}$, \\ Moisés Sesion de M. Neto ${ }^{1}$, Semirames do Nascimento Silva ${ }^{1}$, Morgana A. Araújo ${ }^{1}$, Airton G. de Oliveira ${ }^{1}$, \\ Roberta de O. S. Wanderley ${ }^{1}$, Joana D’arc P. Matos ${ }^{2}$, Larissa M. de Sousa Rodrigues ${ }^{1}$, Maria Suiane de Moraes ${ }^{1}$, \\ Ana Paula M. de Sousa ${ }^{1}$, Francislaine Suelia dos Santos ${ }^{1}$, Lidia P. S. Nogueira ${ }^{1}$, \\ Raimundo Calixto Martins Rodrigues ${ }^{3}$, Gilberto Saraiva Tavares Filho ${ }^{4}$ \\ \& Magaly Morgana Lopes da Costa ${ }^{5}$ \\ ${ }^{1}$ Federal University of Campina Grande, Campina Grande, Brazil \\ 2 Jundiai Agricultural School, Food Technician, Federal University of Rio Grande do Norte, Natal, Brazil \\ ${ }^{3}$ Department of Agricultural Engineering, State University of Maranhão, São Luís, Brazil \\ ${ }^{4}$ Federal University of San Francisco Valley, Juazeiro, Brazil \\ ${ }^{5}$ Brazil Teacher of the Paraíba State Network, São Bento, Brazil \\ Correspondence: Mailson Gonçalves Gregório, Federal University of Campina Grande, Campina Grande, PB, \\ Brazil. E-mail: gregoriomailson@gmail.com
}

Received: October 7, 2020

doi:10.5539/jas.v12n12p163
Accepted: November 4, 2020

Online Published: November 15, 2020

URL: https://doi.org/10.5539/jas.v12n12p163

\begin{abstract}
This study developed and evaluated the efficiency of methods to produce hydroalcoholic extract of Bishop's Crown pepper. Analyses were conducted to investigate the effects of independent variables (ethanol concentration of the extracting solution and resting time) over the dependent variables (percent yield, acidity, carotenoids, phenolic compounds, anthocyanin content and vitamin C). The interactions between the variables were studied through seven factorial experiments. Percent yield (Y\%), carotenoids, phenolic compounds and vitamin $\mathrm{C}$ were the most satisfactory responses found in this research. The ethanol concentration of the extracting solution (ES) presented significant effect in the $\mathrm{Y} \%$, showing better results for extracts produced with a 55\%-ethanol ES, while carotenoids, phenolic compounds and vitamin $\mathrm{C}$ displayed significant differences according to the ethanol concentration, being these substances found in higher concentrations in extracts produced with the use of an $85 \%$-ethanol ES. Therefore, the higher the ES ethanol concentration, higher is the retention of the bioactive compounds.
\end{abstract}

Keywords: low factorial design, statistical behavior, extraction, bioactive compounds

\section{Introduction}

There is a large variety of species of peppers of the genus Capsicum, which belongs to the Solanaceae family. Their origin is connected to the tropical, and especially the humid, zones in America. Peppers have nutritional and pharmacological properties, and are used in alternative medicine (Kim et al., 2010; Lahbib et al., 2017; Meghvansi et al., 2010).

The Bishop's Crown pepper (Capsicum baccatum var.), also known as Cambuci pepper, is one of the most consumed condiments in South America, however there are few studies and data in the literature regarding its chemical composition and possible biological properties. Recent studies have shown that extracts produced from C. Baccatum have antioxidant properties (Allemand et al., 2016; Zimmer et al., 2012).

Nowadays, there is relevant interest in producing and studying extracts from natural sources that have bioactive properties and potential to be used in the food industry, for instance, in the replacing synthetic food colorings for natural ones, and also for their potential antioxidant agents. The final quality of the extracts is related to all the factors to which the material is exposed during the production process, making it necessary to study each factor and their impact on the final product individually. 
The use of a planning matrix and/or factorial experiments is of great interest in processes of various natures, once experiments are conducted and tested for all possible combination, being analyzed the levels of each factor and variable, as well as identifying each level as an experiment itself. Due to that, factorial experiments aim to define in a quantitative manner the impact of each factor on the process, making it possible for researchers to reach results with a lower number of experiments, leading to fewer expenses, time investment, and resources (Neto et al., 2010).

During the extraction of bioactive compounds from vegetable products several factors impact the final-product characteristics, such as the shape and size of the material, the type and concentration of the extracting solution (ES) used, as well as the time during which the sample and the ES remain in contact. Therefore, the extracts obtained may contain different concentrations of bioactive compounds (Vongsak et al., 2013).

Facing the challenges exposed, this study developed and evaluated the efficiency of methods to produce hydroalcoholic extract of Bishop's Crown pepper, through the investigation of the effects of the ethanol concentration of extracting solutions (ES) and resting time, over percent yield, acidity and bioactive compounds (carotenoids, phenolic compounds, anthocyanin content and vitamin C).

\section{Method}

\subsection{Raw Material and Research Site}

The Bishop's Crown peppers were acquired in the local commerce of the city of Pombal, Paraíba, Brazil, being then transported to the Food Chemistry and Biochemistry Laboratory of the Federal University of Campina Grande campus in the same city where samples were acquired.

\subsection{Production of Bishop's Crown Pepper Hydroalcoholic Extract}

From the peppers acquired, only the ones in perfect maturation stage and with no visible physical damage were selected to go under a cleaning process for removing any residues and potential microorganisms in the fruits. For the production of the extract, the peppers had seeds removed and were processed in a mixer (M-08) to obtain a homogeneous paste, which was added to the extracting solution (ethanol) in different concentrations $(55 \%, 70 \%$, and $85 \%$ ) and resting times $(8 \mathrm{~h}, 16 \mathrm{~h}$, and $24 \mathrm{~h}$ ), as detailed in the Table 1 .

Table 1. Independent variables (factorial design $2^{2}+3$ )

\begin{tabular}{lll}
\hline Experiments & Ethanol Concentration (\%) & Resting time $(\mathrm{h})$ \\
\hline 1 & 55 & 8 \\
2 & 55 & 24 \\
3 & 85 & 8 \\
4 & 85 & 24 \\
5 & 70 & 16 \\
6 & 70 & 16 \\
7 & 70 & 16 \\
\hline
\end{tabular}

\subsection{Calculating the Percent Yield of the Extracts}

The percent yield (Y\%) was calculated according to Rodrigues et al. (2011), considering the relation between the volume of the final extract (VFE) and the volume of the initial extract (VIE) before filtration and evaporation of the solvent. The following equation was used:

$$
\mathrm{Y} \%=(\mathrm{VFE} / \mathrm{VIE}) \times 100
$$

\subsection{Chemical Characterizing of the Extracts}

The extracts were characterized in triplicate for the following physicochemical coatings: total titratable acidity and vitamin $\mathrm{C}$ according to the methodology of the Adolfo Lutz Institute (Brazil, 2008). Carotenoids were determined according to Lichtenthaler (1987), the anthocyanins were determined according to the Francis method (1982) and the determination of total phenolic compounds was performed by the Folin-Ciocalteu method, described by Waterhouse (2006).

\subsection{Statistical Analysis}

The studies of the dependent variables were treated used using the graphs of parentheses and the contour surface methodology. ANOVA was applied to test the meaning of the interaction process $(p<0.05)$. To visualize the 
effect of independent variables on the functions of the evaluated responses, they were on the contour surface. This statistical behavior was performed with the software (StatSoft, Inc., 2004).

\section{Results and Discussion}

From the results of this study, it is possible to verify the effects that each independent variable has for the responses analyzed. Regarding the final percent yields (Y\%), the methods used in this study for producing the hydroalcoholic extracts of Bishop's Crown pepper were shown to be satisfactory since all extracts presented percent yields higher than $68 \%$. However, the $\mathrm{Y} \%$ changed according to the ethanol concentration used in the extracting process - the extracts which were produced with ES containing lower concentration of ethanol presented higher $\mathrm{Y} \%$ - which allows to infer that the solvent concentration had a significant effect, as shown in the $\mathrm{Y} \%$ Pareto chart (Figure 1A).

For better comprehending of the statistic data, the $\mathrm{Y} \%$ contour plot (Figure 1B) displays a more intense red region in the variable 'ethanol concentration', which provides evidence that the extracts produced with an ES of $55 \%$ ethanol presented higher Y\%, varying from $85.26 \%$ to $91.99 \%$, respectively. On the other hand, extracts that were produced with $85 \%$-ethanol ES presented the lowest Y\% when compared to the other extracts. Such results lead to the understanding that the higher the concentration of ethanol in the ES is, higher will be the time needed to promote the evaporation of the alcohol, leading to a lower $\mathrm{Y} \%$ of the extract due to this chemical behavior.

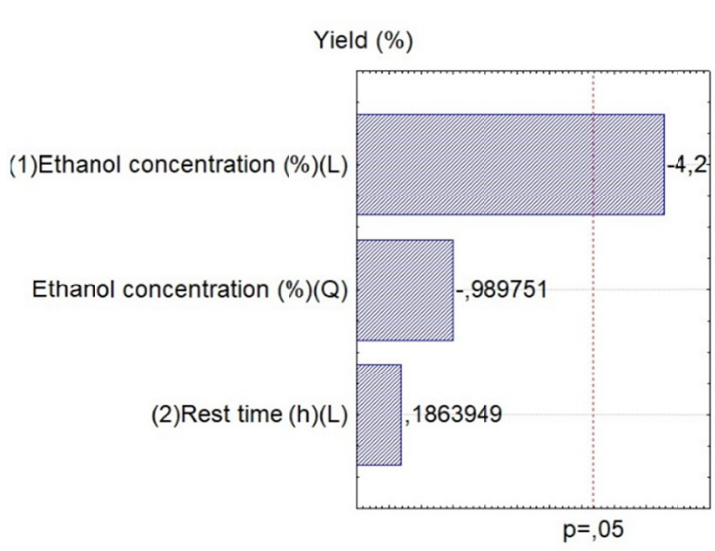

(A)

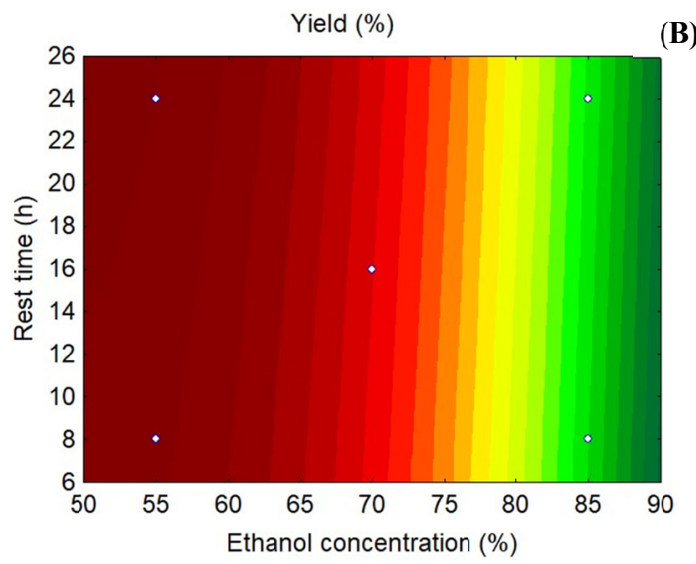

Figure 1. Pareto Chart (A) and Contour Surface (B) for extract yield (\%)

Regarding the total acidity of the extracts, a gradual increase was observed on the organic acids, leading to the inference that the higher the ethanol concentration in the ES and the time, higher the acidity of the final extracts. The Pareto chart for this depend variable (Figure 2A), however, shows that the two variables analyzed did not have a statistically significant impact on the final concentration of organic acids in the extracts.

In the total acidity contour plot (Figure $2 \mathrm{~B}$ ), it is possible to observe a region with darker shades distributed among the variables. The highest concentrations of organic acids varied from 0.13 to $0.15(\mathrm{~g} / 100 \mathrm{~g})$ in citric acid. These values were obtained in the ethanol concentration variable, corresponding to extracts produced using an $85 \%$ ethanol ES. Similar behavior was observed in the variable time, showing that the extracts that remained combined with the ES for a longer period presented higher concentrations of organic acids. Gregorio et al. (2020) obtained similar results for hydroalcoholic extracts of chili peppers with values ranging from 0.07 to $0.13(\mathrm{~g} / 100$ g). 


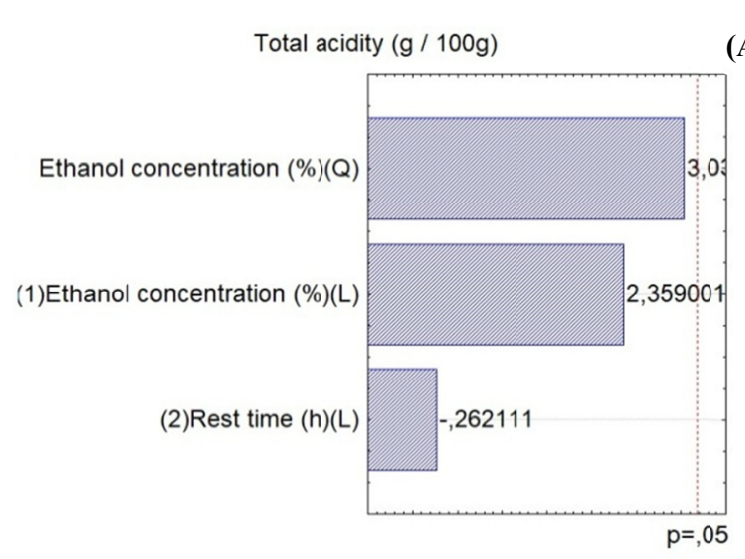

(A)

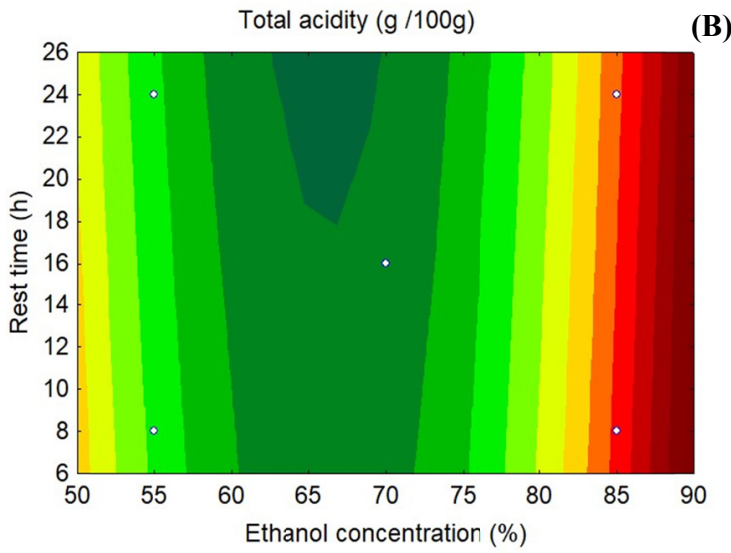

Figure 2. Pareto Chart (A) and Contour Surface (B) for total acidity

The analysis showed that the variable ethanol concentration promoted a significant increase in the levels of carotenoids in the extracts, as displayed in the Figure 3A. The variable time did not present significant effect on the levels of total carotenoids in the extracts, which shows that in the conditions of this study, the time of contact of the extract with the ES did not have a significant impact on the levels of carotenoids. This behavior is relevant once the industry seeks for high-quality products, with less processing time, which reduces companies' operational expenses.

For better comprehension of this statistical behavior, the Figure 3B has a red region of more intense color in the ethanol concentration variable, showing that extracts produced with the use of an $85 \%$-ethanol ES obtained the highest concentrations of carotenoids $(200-220 \mu \mathrm{g} / 100 \mathrm{~g})$. Analyzing the graph, the extracts produced with $55 \%$-ethanol ES presented the lowest concentration of total carotenoids.

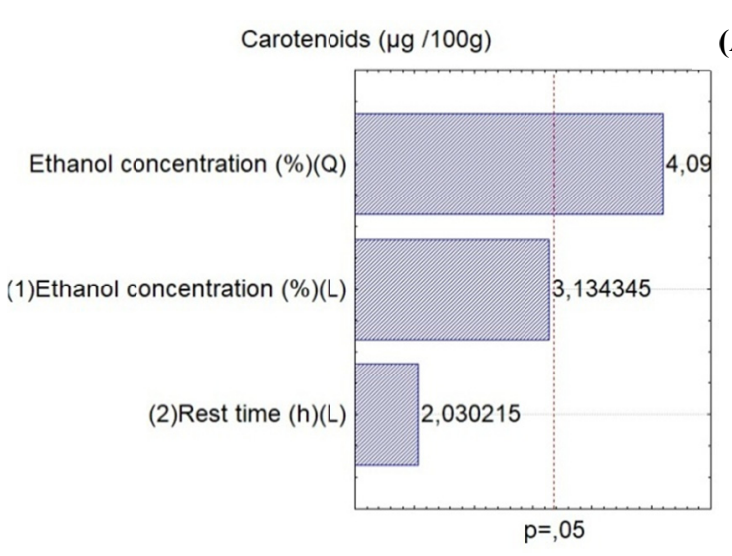

(A)

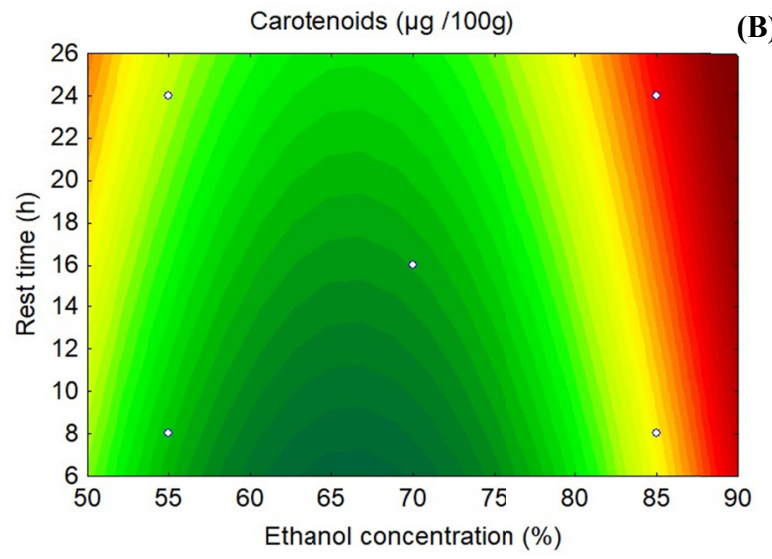

Figure 3. Pareto Chart (A) and Contour Surface (B) for carotenoids

When it comes to the anthocyanin content, the two variables analyzed (ethanol concentration and resting time) did not present significant effects in the final concentration of anthocyanins in the extracts, as show in Figure $4 \mathrm{~A}$.

Although statistical significance was not observed in all operational conditions analyzes, it is seen that the levels of anthocyanins were slightly higher in both dependent variables. For the resting time variable, the extracts produced in a 24 h-resting-time period of contact with the ES had a higher concentration of anthocyanins when compared to the other resting times. The same was observed for the ES ethanol concentration, when extracts produced with the use of ES with hgiher concentrations of ethanol also contained higher levels of anthocyanins (Figure 4B). 


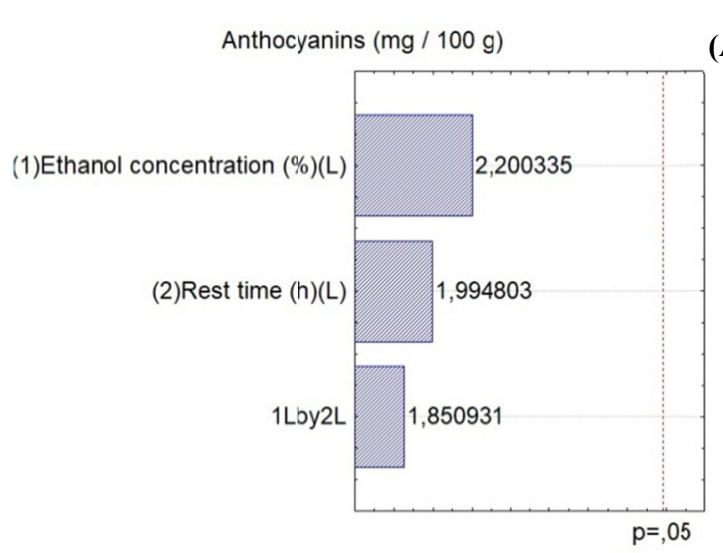

(A)

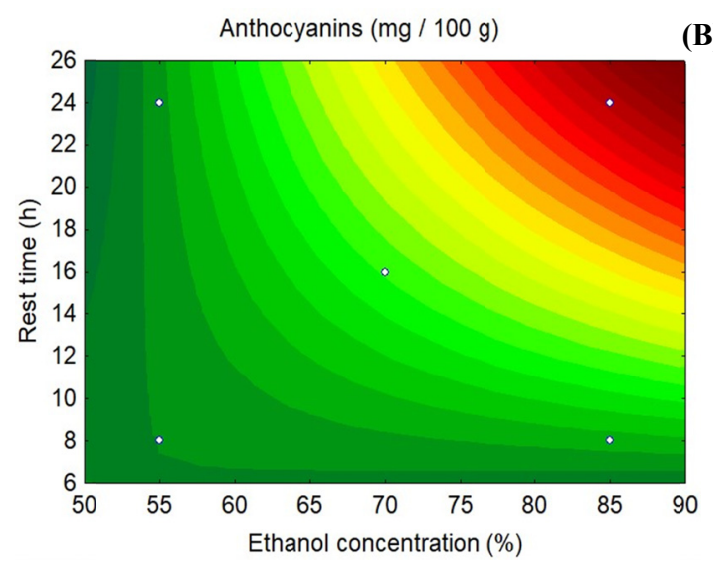

Figure 4. Pareto Chart (A) and Contour Surface (B) for anthocyanin content

Phenolic compounds are part of the chemical composition of plants, acting on the plants' protection, promoting high resistance to microorganisms and several agricultural plagues. Their presence in food can influence nutritional and sensorial aspects, since they modify the color, texture, bitterness and astringency. In most vegetables, the phenolic compounds are the most abundant antioxidants (Everette et al., 2010).

The levels of phenolic compounds in the extracts found in the analysis had a similar behavior to the previously discussed. The ES ethanol concentration led to a significant increase in the level of phenolic compounds in the extracts, as shown in the Figure 5A.

Through the observation of the contour plot (Figure 5B), it is noticeable that the levels of phenolic compounds in extracts produced with an $85 \%$-ethanol ES varied from $2565.15 \mathrm{mg} / 100 \mathrm{~g}$ to $3058.78 \mathrm{mg} / 100 \mathrm{~g}$, and also that the variable time did not impact the final levels of these compounds. These findings are important because they show that the three different resting times during which the samples and the ES kept combined did not cause a statistical difference in the final levels of phenolic compounds in the hydroalcoholic extracts of Bishop's Crown pepper.
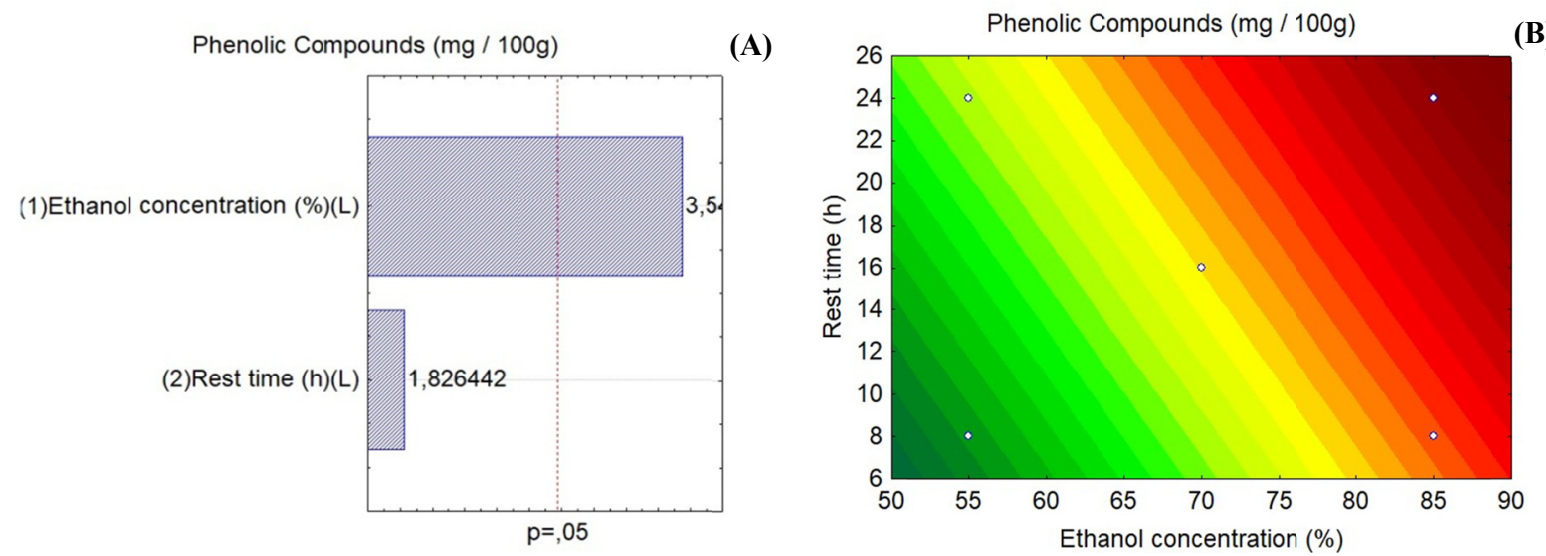

Figure 5. Pareto Chart (A) and Contour Surface (B) for phenolic compounds

Vitamin $\mathrm{C}$ is one of the main chemical components in peppers, but the concentration of this substance may vary according to the pepper species, cropping techniques and/or agricultural handling. The extracts produced with an $85 \%$-ethanol ES presented higher amounts of vitamin C, promoting a significant difference when compared to extracts produced with ES that had lower concentrations of ethanol (Figure 6A).

The Figure $6 \mathrm{~B}$ allows a better analysis of this statistical behavior. The concentrations of vitamin $\mathrm{C}$ in extracts produced with $85 \%$-ethanol ES varied from $150.16 \mathrm{mg} / 100 \mathrm{~g}^{-1}$ to $170.44 \mathrm{mg} / 100 \mathrm{~g}^{-1}$. Gregorio et al. (2020) 
inferior results for vitamin $\mathrm{C}$ of the hydroalcoholic extracts of chilli pepper. Thus, it can be said that the vitamin $\mathrm{C}$ content may vary according to the species of pepper.
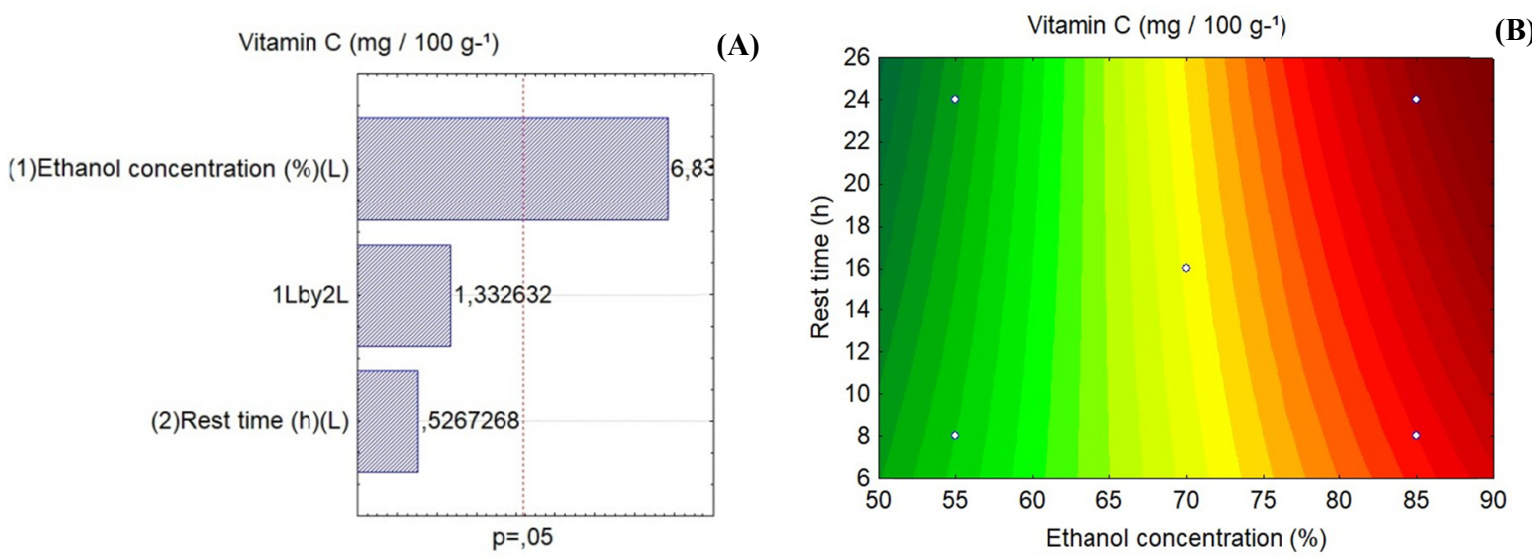

Figure 6. Pareto Chart (A) and Contour Surface (B) for vitamin C

In addition to that, it is important to highlight that the role of vitamin $\mathrm{C}$ as an antioxidant provides the neutralization of free radical that are associated with premature aging, as well as the development of heart diseases and cancer.

\section{Conclusions}

The results of this study have shown that the total acidity and the concentration of anthocyanins did not present significant differences for both variables analyzed. However, the production process led to a significant difference in the percent yields of the extracts, which was associated with the concentration of ethanol of extracting solution (extracts produced with a 55\%-ethanol ES had the highest percent yields).

The carotenoids, phenolic content and vitamin $\mathrm{C}$ presented similar statistical behavior, except that in an inverted manner - the extracts produced with the use of an 85\%-ethanol ES had the highest concentrations of the three bioactive compounds, displaying significant differences when compared to extracts produced with ES with ethanol concentrations lower than $85 \%$. The time during which the ES were combined with the samples (resting time) did not have a significant impact in the dependent variables analyzed in this study.

\section{References}

Allemand, A., Leonardi, B. F., Zimmer, A. R., Moreno, S., Romao, P. R., \& Gosmann, G. (2016). Red pepper (Capsicum baccatum) extracts present anti-inflammatory effects in vivo and inhibit the production of TNF-alpha and NO in vitro. J Med Food, 19, 759-767. https://doi.org/10.1089/jmf.2015.0101

Brasil, Instituto Adolfo Lutz. (2008). Métodos fisico-químicos para análise de alimentos (4th ed., Vol. 1, p. 1020). São Paulo: Instituto Adolfo Lutz.

Everette, J. D., Bryant, Q. M., Green, A. M., Abbey, Y. A., Wangila, G. W., \& Walker, R. B. (2010). Thorough study of reactivity of various compound classes toward the Folin Ciocalteou reagent. J Agric Food Chem, 58, 8139-8144. https://doi.org/10.1021/jf1005935

Francis, F. J. (1982). Análise de antocianinas. In P. Markakis (Ed.), Antocianinas como corantes alimentares (pp. 181-207). Nova York: Academic Press.

Gregorio, M. G., Medeiros, M. L. S., Sousa, T. C. A., Medeiro, N. S. M. S., Silva, L. P. F. R., Paiva, F. J. S., ... Oliveira, A. P. (2020). Influence of the independent variables of the process of elaboration of the hydroalcoholic extract of malagueta chili pepper on the bioactive compounds. Sylwan, 164(8), 383-390.

Kim, G. D., Lee, Y. S., Cho, J. Y., Lee, Y. H., Choi, K. J., Lee, Y. H. T., ... Moon, J. H. (2010). Comparison of the content of bioactive substances and the inhibitory effects against rat plasma oxidation of conventional and organic hot peppers (Capsicum annuum L.). J Agric Food Chem, 58, 12300-12306. https://doi.org/ $10.1021 / \mathrm{jf} 1028448$ 
Lahbib, K., Dabbou, S. E. L. B. S., Pandino, G., Lombardo S, E. L., \& Gazzah, M. (2017). Variation of biochemical and antioxidant activity with respect to the part of Capsicum annuum fruit from Tunisian autochthonous cultivars. Industrial Crops and Products, 104, 164-170. https://doi.org/10.1016/j.indcrop. 2017.04.037

Lichtenthaler, H. K. (1987). Chlorophylls and carotenoids: pigments of photosynthetic biomembranes. Methods in Enzymology, 148, 362-385.

Meghvansi, M. K., Siddiqui, S. K. M., Gupta, V. K., Vairale, M. G., Gogoi, H. K., \& Singh, L. (2010). Naga chilli: A potential source of capsaicinoids with broad-spectrum ethnopharmacological applications. $J$ Ethnopharmacol, 132, 1-14. https://doi.org/10.1016/j.jep.2010.08.034

Neto, B. B., Scarminio, I. S., \& Bruns, R. E. (2010). Como fazer experimentos: Aplicações na ciência e na indústria. Bookman Editora.

Rodrigues, T. S., Guimarães, S. F., Rodrigues, R. G., \& Gabriel, J. V. (2011). Métodos de secagem e rendimento dos extratos de folhas de Plectranthus barbatus (boldo-da-terra) e P. ornatus (boldo-miúdo). Rev Bras Pl Med, 13, 587-590. https://doi.org/10.1590/S1516-05722011000500014

StatSoft, Inc. (2004). Statistica, Version 7.0. StatSoft, Inc., Tulsa, OK, USA.

Vongsak, B., Sithisarn, P., Mangmool, S., Thongpraditchote, S., Wongkrajang, Y., \& Gritsanapan, W. (2013). Maximizing total phenolics, total flavonoids contents and antioxidant activity of Moringa oleifera leaf extract by the appropriate extraction method. Industrial Crops and Products, 44, 566-571. https://doi.org/ 10.1016/j.indcrop.2012.09.021

Waterhouse, A. (2006). Folin-ciocalteau micro method for total phenol in wine. American Journal of Enology and Viticulture, 3-5.

Zimmer, A. R., Leonardi, B., Miron, D., Schapoval, E., Oliveira, J. R., \& Gosmann, G. (2012). Antioxidant and anti-inflammatory properties of Capsicum baccatum: From traditional use to scientific approach. $J$ Ethnopharmacol, 139, 228-233. https://doi.org/10.1016/j.jep.2011.11.005

\section{Copyrights}

Copyright for this article is retained by the author(s), with first publication rights granted to the journal.

This is an open-access article distributed under the terms and conditions of the Creative Commons Attribution license (http://creativecommons.org/licenses/by/4.0/). 